\title{
Differences between MFI- and MEL-Type Zeolites in Paraffin Hydrocracking
}

\author{
Th. L. M . M aesen, ${ }^{* 1}, 1$ M. Schenk, $\nmid$ T. J. H . V lugt,,${ }^{2}$ and B. Smit $\dagger$ \\ *Z eolyst I nternational, PQ R\&D Center Conshohocken, Pennsylvania 19428-2240; and †D epartment of Chemical Engineering, \\ U niversity of A msterdam, N ieuwe A chtergracht 166, 1018 WV A msterdam, The N etherlands
}

R eceived D ecember 11, 2000; revised July 1, 2001; accepted J uly 1, 2001

\begin{abstract}
A critical evaluation of published paraffin hydroconversion data shows that ME L-type zeolites preferentially hydrocrack paraffins where two methyl groups are separated by a methylene group, whereas MFI-type zeolites prefer paraffins with geminal methyl groups (preferably at the central carbon atom). Due to this difference in hydrocracking pathway, ME L-type zeolites will hydroisomerize a higher percentage of the feed than MFI-type zeolites at low temperature, while the reverse is true at high temperature. The free energies of adsorption calculated by means of configurational bias Monte Carlo (CBMC) molecular simulations are used to explain these differences in selectivity. They show that the MEL- and MFI-type zeolites favor the formation and hydrocracking of the dimethyl paraffins that have a shape commensurate with that of their pores. They indicate that the higher paraffin hydroisomerization selectivity of the MEL-type zeolites can also be explained by their higher selectivity for adsorbing linear rather than branched paraffins at high paraffin loading. At low paraffin loading this difference in adsorption selectivity disappears. B oth temperature and loading effects could resolve a disparity in the literature between $n$-decane and $n$-heptane hydroisomerization selectivity data. (c) 2001 A cademic Press
\end{abstract}

Key Words: molecular simulations; hydrocracking; zeolites; free energies of adsorption.

\section{INTRODUCTION}

Catalysts based on M FI-type zeolites are widely used in many areas of the oil and petrochemical industries, because of their ability to catalyze reactions shape selectively (1). They are used in the catalytic upgrading of fuel oil, because they selectively adsorb and hydrocrack wax-like, long-chain normal paraffins into smaller, shorter-chain products (1-4). $\mathrm{N}$ otwithstanding the proven track record of M FI-type zeolites in fuel oil upgrading, a catalyst of comparable activity, but with a higher selectivity for hydroisomerization than for

\footnotetext{
${ }^{1}$ C urrent address: Chevron R esearch and Technology Co., 100 Chevron Way 10-1412, R ichmond, CA 94802. E-mail: tmsn@chevron.com.

${ }^{2}$ Current address: Instituut-L orenz for Theoretical Physics, P.O. Box 9506, 2300 R A L eiden, The N etherlands.
}

hydrocracking would be desirable as it would yield more valuable fuel oil and less gas. M E L - and M FI-type zeolites are comparable in terms of activity (5-10). This is probably related to the similarity of the framework density and the pore size of these structures (11). D espite these similarities, some studies have suggested that M E L-type zeolites hydroisomerize more paraffins than M FI-type zeolites, at any given paraffin hydroconversion level (5-7). This intrinsic high hydroisomerization selectivity was first postulated based on studies using n-decane $\left(n-C_{10}\right)$ as a model feed (5), refuted based on studies using n-heptane $\left(n-C_{7}\right)$ as a feed (8), and then corroborated by studies using complex feed stocks $(6,7)$. It is not clear how the differences in structure between M FI- and M E L-type zeolites translate to the differences in catalytic behavior (8).

Both M FI- and MEL-type zeolites have three-dimensional $\sim 0.55-\mathrm{nm}$ channels. The M FI topology consists of intersecting straight and sinusoidal channels, whereas the $M E L$ topology has only straight channels. Consequently, the structure and size of the single M FI-type channel intersection is significantly different from the two distinct M E L type intersections (Fig. 1) $(9,11)$.

Before the advent of molecular simulations, relating the differences between the M FI- and MEL-type zeolite structures to differences in shape selectivity was hindered by a lack of microscopic information on the adsorption and diffusion inside these zeolite structures $(2,9)$. Fortunately, molecular simulations capable of yielding such information on a molecular level have become available $(12,13)$. H owever, simulating the adsorption of long-chain or branched paraffins with conventional molecular simulation techniques would require excessive CPU time. Therefore most molecular simulations are energy minimization studies that ignore entropic contributions (14). The configurational bias $\mathrm{M}$ onte $\mathrm{Carlo}$ ( $\mathrm{CBM}$ C) technique, a recent development in molecular simulations, circumvents this problem and allows calculation of the Henry coefficients, the free energy of adsorption and the adsorption enthalpy at zero coverage, the diffusion coefficients, and the adsorption isotherms for paraffins in microporous silica structures 


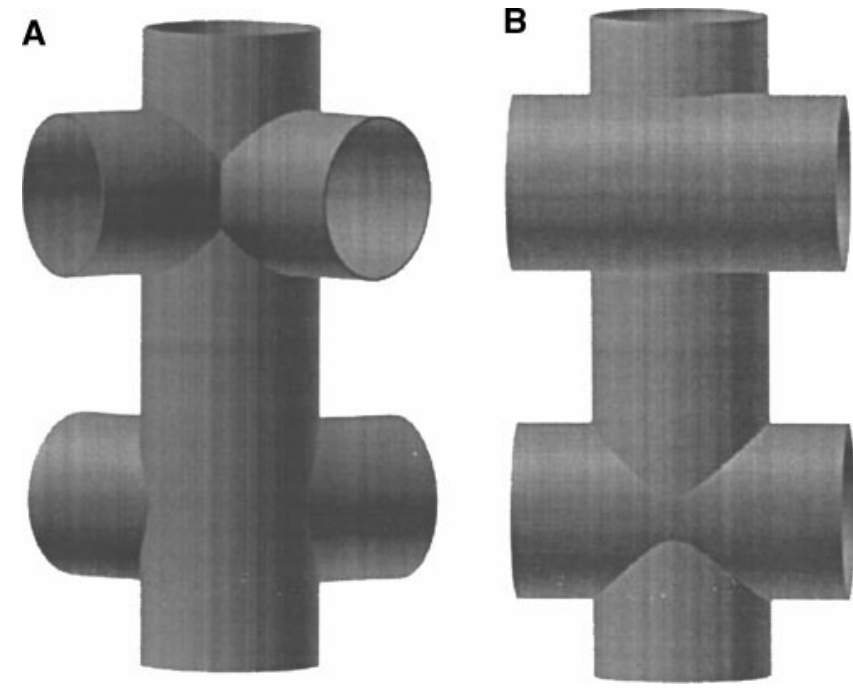

FIG . 1. Sketch of the M FI- (A) and MEL-type (B) channel intersections. The zeolites have a similar pore diameter $(0.55 \mathrm{~nm})$ and structure. The principle difference is that M FI contains both straight and sinusoidal channels, while all M E L -type channels are straight. There is only one M FItype channel intersection. M E L -type channel intersections are either large (top) or small (bottom).

$(12,15-17)$. The free energy of adsorption quantifies how a zeolite structure alters the gas phase free energy of formation of a hydrocarbon. The more a zeolite structure decreases the free energy of formation for a particular type of paraffin, the more likely it is to form and subsequently hydroisomerize or hydrocrack that paraffin (12).

Here we show how the thermodynamic data obtained by molecular simulations can shed some light on the differences in paraffin hydroconversion between $\mathrm{MFI}$ - and $M E L$-type zeolites. A s the thermodynamic adsorption data relate to the shape selective properties that are intrinsic to a zeolite structure, we develop a criterion to identify catalytic data that are unimpaired by mass transport or hydrogenation rate limitations. $A$ subsequent scrutiny of the published $n-C_{7}(8,18)$ and $n-C_{10}(5,19-23)$ hydroconversion data using this criterion shows intrinsic differences in paraffin hydroconversion between M FI- and M E L -type zeolites. Simulated $\mathrm{C}_{10}$ adsorption data are then used to explain the observed differences in the hydroconversion of $n-\mathrm{C}_{10}$ and of complex feedstocks and the absence of such differences in a publication (8) on the hydroconversion of $n-C_{7}$.

\section{MOLECULAR SIMULATION METHODS}

In conventional simulations, $\mathrm{M}$ onte $\mathrm{C}$ arlo moves insert a molecule in a zeolite in a random position. For long-chain hydrocarbons almost always one of the atoms of such a molecule will have an overlap with the zeolite framework. A s a consequence, such moves have a very low acceptance rate. Therefore, the application of the conventional M onte Carlo technique is limited to the adsorption of very small probe molecules. In the CBM C scheme the molecules are grown atom by atom in such a way that the empty channels inside the zeolite are found. The bias introduced by this growing scheme is removed by adjusting the acceptance rules (24).

The CBMC simulations model uses single interaction centers (united atoms) to represent the $\mathrm{CH}_{3}, \mathrm{CH}_{2}$, and $\mathrm{CH}$ groups in the linear and branched paraffins. The bonded interactions include bond-bending and torsion potentials. $\mathrm{D}$ ispersive interactions with the oxygen atoms of the silica structure are assumed to dominate the silica-paraffin interactions. The zeolite is modeled as a rigid crystal (25), consisting exclusively of $\mathrm{SiO}_{2}$, so as to make the calculation of paraffin-zeolite interactions efficient. This allows the use of special interpolation techniques $(26,27)$ to obtain the correct paraffin conformation at any given temperature. M ore details about the simulation method and the force fields are described elsewhere (24).

The sizes of the molecules and the energy parameters have been fitted to the adsorption enthal pies and the H enry coefficients of linear and mono-branched paraffins in aluminum-free M FI-type silicas (24). The resultant force field reproduces the $\mathrm{H}$ enry coefficients, the changes in the free energy of formation (i.e., the free energy of adsorption), the adsorption enthalpies, and isotherms for linear and mono-branched paraffins. The same force field also reproduces these parameters for microporous silica topologies other than the M FI-type remarkably well (28).

The simulations consist of three different trial moves:

1) $D$ isplacement of a chain: a chain is selected at random and given a random displacement. The maximum displacement was taken such that $50 \%$ of the moves were accepted.

2) R otation of a chain: a chain is selected at random and given a random rotation around the center of mass. The maximum rotation angle was selected such that $50 \%$ of the moves were accepted.

3) Complete regrowth of the chain: a chain is selected at random and is completely regrown at a randomly selected position. D uring this step data is collected from which the Henry coefficient is determined.

The calculation of an adsorption isotherm of a mixture of alkanes requires a simulation in the grand-canonical ensemble (24). Such a simulation employs the same initial two steps as one in the NVT ensemble, but diverges at the third step:

3) Partial regrowth of the chain: a randomly selected part of a randomly selected alkane is regrown.

4) Exchange with the reservoir: an alkane is randomly added or removed from the microporous silica structure.

5) Identity change: an attempt is made to change the isomer type of a randomly selected molecule.

The relative probabilities for attempting these moves in an N V T simulation were such that $10 \%$ of the total number 
of moves was a displacement, $10 \%$ a rotation, and $80 \%$ a regrowth of the entire molecule. A simulation consists of $5 \times 10^{6} \mathrm{M}$ onte Carlo steps. In the grand-canonical simulations the probabilities were $15 \%$ displacement, $15 \%$ rotation, $15 \%$ partial regrowth, $50 \%$ exchange, and $5 \%$ identity change. A typical simulation requires some $10^{7}$ Monte Carlo steps. The calculation of the change in the free energy of formation, the $\mathrm{H}$ enry coefficient and the adsorption enthalpy at zero coverage requires two simulations in the NVT ensemble; one simulation of a paraffin inside an M FI- or MEL-type silica and another simulation in the ideal gas situation (24).

In each simulation the $\mathrm{R}$ osenbluth factor is calculated in the molecular sieve, $W_{\text {sieve, }}$ and in the ideal gas phase $W_{\text {gas }}$. The free energy of adsorption $\left(\Delta G_{\text {ads }}(\mathrm{J} / \mathrm{mol})\right)$ is the difference between the free energy of formation of a molecule in the molecular sieve $\left(\Delta G_{\text {sieve }}^{\mathrm{f}}(\mathrm{J} / \mathrm{mol})\right)$ and the free energy of formation of one in the ideal gas phase $\left(\Delta G_{\text {gas }}^{f}(\mathrm{~J} / \mathrm{mol})\right)$. A the limit of very low adsorbate loading and pressure, the Helmholtz and $G$ ibbs free energies converge, so that they follow from the ratio of the R osenbluth factors $(27,29)$ :

$$
\Delta G_{\text {ads }}=\Delta G_{\text {sieve }}^{\mathrm{f}}-\Delta G_{\text {gas }}^{\mathrm{f}}=-R \cdot T \cdot \ln \left(W_{\text {sieve }} / W_{\text {gas }}\right) .
$$

In this formula $R$ is the gas constant $(8.3144 \mathrm{~J} / \mathrm{mol} \mathrm{K})$ and $T$ (K) the absolute temperature.

A ccording to this formalism, the relationship between the free energy of adsorption and the Henry coefficient, $K_{\mathrm{H}}(\mathrm{mol} / \mathrm{kg} \mathrm{Pa})$ is $(27,29)$

$$
\Delta G_{\mathrm{ads}}=-R \cdot T \cdot \ln \left(K_{\mathrm{H}} \cdot D \cdot R \cdot T\right) .
$$

In this formula $D$ is the framework density $(1.79 \times$ $10^{3} \mathrm{~kg} / \mathrm{m}^{3}$ for M FI-type silicas and $1.77 \times 10^{3} \mathrm{~kg} / \mathrm{m}^{3}$ for ME L-type silicas (11)).

\section{RESULTS AND DISCUSSION}

$C_{7}$ hydroconversion mechanism. The hydroconversion of $n-C_{7}$ on M FI- (18) and MEL-type (8) zeolites can be described as a series of consecutive reactions (30). First, $n-\mathrm{C}_{7}$ hydroisomerizes into iso-heptane $\left(i-C_{7}\right)$, then into dibranched heptanes (henceforth referred to as ii- $C_{7}$ ), which subsequently hydrocrack into iso-butane $\left(i-\mathrm{C}_{4}\right)$ and propane $\left(\mathrm{C}_{3}\right)(28,30)$ :

$$
n-\mathrm{C}_{7} \rightleftarrows i-\mathrm{C}_{7} \rightleftarrows i i-\mathrm{C}_{7} \rightarrow i-\mathrm{C}_{4}+\mathrm{C}_{3} .
$$

The equilibration between the different $C_{7}$ isomers occurs inside the M FI- and MEL-type pores. It is not necessarily observed directly in the product distribution due to the interference of diffusion and-occasionally-of premature hydrocracking.

Diffusion affects the product slate by selectively trapping the slowly diffusing $i-C_{7}(13,31,32)$ and the even more slowly diffusing ii- $\mathrm{C}_{7}$ with proximate methyl groups $(12,33-$ 36) inside the M FI - and M E L -type pores. The more slowly a $\mathrm{C}_{7}$ isomer diffuses, the greater the chance that it is hydroisomerized into ii- $\mathrm{C}_{7}$ with either geminal methyl groups or with methyl groups separated by one methylene $\left(-\mathrm{CH}_{2-}\right)$ group (quasi-vicinal methyl groups). These are subsequently hydrocracked into a fast-diffusing $i-C_{4} / C_{3}$ product pair.

Premature hydrocracking affects the product slate when $\mathrm{a} \mathrm{C}_{7}$ isomer is hydrocracked before it has hydroisomerized into geminal or quasi-vicinal ii- $C_{7}$. It yields an $n-C_{4} / C_{3}$ instead of an $i-C_{4} / C_{3}$ product pair $(28,37-39)$. It occurs when there are multiple transformations at acid sites inside pores that significantly limit sorbate mobility $(14,28,38,40)$. This happens when the hydrogenation function is insufficiently active as compared to the acid function $(38,41-43)$ or when the mass transport between the hydrogenating sites and the acid sites is the rate-limiting step $(18,38,41,43)$.

$\mathrm{C}_{10}$ hydroconversion mechanism. It has been shown that $n-C_{7}$ and $n-C_{10}$ share essentially the same hydroconversion mechanism $(37,39,44,45,46)$. The only difference between $n-C_{7}$ and $n-C_{10}$ is that the latter can hydroisomerize into a tribranched "iii- $\mathrm{C}_{10}$ " isomer with both geminal and quasi-vicinal methyl groups (i.e., with methyl groups on $\alpha, \alpha, \gamma$ positions) (39,44-48) before hydrocracking, whereas the former is too short to form the equivalent iii- $C_{7}$ hydrocracking precursor. This difference is irrelevant when studying $\mathrm{MFI}$ - and MEL-type frameworks, because the shape-selective constraints imposed by these frameworksimpede the formation of the transition state required for such $\mathrm{iii}_{-} \mathrm{C}_{10}$ isomers $(5,12,49)$. Thus, for the purpose of this paper, the hydroconversion of $n-C_{10}$ may be regarded as completely analogous to that of $n-C_{7}: n-C_{10}$ hydroisomerizes into iso-decane $\left(i-\mathrm{C}_{10}\right)$ and dibranched decanes (henceforth referred to as $\mathrm{ii}-\mathrm{C}_{10}$ ), and subsequently ii- $\mathrm{C}_{10}$ hydrocracks to give four product pairs-a monomethyl paraffin $i-C_{x}$ and a linear paraffin $n-C_{(10-x)}(x$ an integer, $4 \leq x \leq 7$ ) (50):

$$
n-\mathrm{C}_{10} \rightleftarrows i-\mathrm{C}_{10} \rightleftarrows \mathrm{ii}-\mathrm{C}_{10} \rightarrow i-\mathrm{C}_{x}+n-\mathrm{C}_{(10-x)} .
$$

A s with $n-\mathrm{C}_{7}$ hydroconversion, the more the $n-\mathrm{C}_{10}$ hydroconversion rate is determined by the rate of the acidcatalyzed reactions, rather than by the mass transport or the hydrogenation rate, the higher the proportion of branched paraffins in the product slate (10).

In view of the striking similarity of the $n-C_{7}$ and the $n-C_{10}$ hydroconversion mechanism it is intriguing why $M E L$-type zeolites reportedly have a higher $n-C_{10}$ hydroisomerization selectivity than M F I-type zeolites (5), but not a higher $n-C_{7}$ hydroisomerization selectivity (8). This study attempts to resolve this puzzle. To some degree resolution can be obtained by scrutinizing the published $n-\mathrm{C}_{10}$ hydroconversion data. 


\section{TABLE 1}

The C rystal Size, the Framework Aluminum D ensity (N (AI) in A toms per U nit C ell), and Zeolite Type of Catalysts O perated at a Partial Hydrogen $\left(\mathrm{p} \mathrm{H}_{2}(\mathrm{kPa})\right)$, Hydrocarbon Pressure ( $\mathrm{p} n-\mathrm{C}_{10}(\mathrm{kPa})$ ), Molar Hydrogento-Hydrocarbon Ratio $\left(\mathrm{H}_{2} / n-\mathrm{C}_{10}(\mathrm{~mol} / \mathrm{mol})\right)$ Require a Certain Temperature for $50 \% n-\mathrm{C}_{10} \mathrm{Hydroconversion}$ $\left(T_{50 \%}(\mathrm{~K})\right)$

\begin{tabular}{|c|c|c|c|c|c|c|c|c|}
\hline Z eolite type: & MFI & $\mathrm{MFI}$ & $\mathrm{MFI}$ & MFI & & $\mathrm{MFI}$ & & MEL \\
\hline Crystal size $(\mu \mathrm{m})$ & $\mathrm{np}^{a}$ & 15 & 6 & 4 by 6 & & 0.1 by 0.5 & & 4 by 6 \\
\hline $\mathrm{N}(\mathrm{A} \mid)$ (at/u.c.) & 5.2 & 2.5 & 1.6 & 3 & & 1.6 & & 3 \\
\hline $\mathrm{pH}_{2}(\mathrm{kPa})$ & 100 & 101 & 350 & 100 & & 2000 & & 100 \\
\hline $\mathrm{p} n-\mathrm{C}_{10}(\mathrm{kPa})$ & 1.4 & 0.7 & 0.9 & 1.5 & & 20 & & 1.5 \\
\hline $\mathrm{H}_{2} / n-\mathrm{C}_{10}(\mathrm{~mol} / \mathrm{mol})$ & 71 & 151 & 389 & 65 & & 100 & & 65 \\
\hline$T_{50 \%}(\mathrm{~K})^{b}$ & 440 & 440 & 440 & 400 & & 520 & & 430 \\
\hline$\% n-C_{10}$ hydroconversion & 4 & $7^{b}$ & $12^{b}$ & $10^{b}$ & 46 & & $93^{b}$ & $49^{b}$ \\
\hline$\% \mathrm{C}_{10}$ hydrocracked & $3-4^{b}$ & 5 & 7 & 5 & 7 & & 50 & 5 \\
\hline$\% i-\mathrm{C}_{5}$ & $25^{b}$ & 31 & $42^{b}$ & 44 & $\mathrm{np}^{a}$ & & $49^{b}$ & $50^{b}$ \\
\hline${ }^{1} / 5 \sum_{x=4}^{7} \% i-\mathrm{C}_{x}$ & $19^{b}$ & 23 & $34^{b}$ & 35 & $\mathrm{np}^{a}$ & & $47^{b}$ & $41^{b}$ \\
\hline $\begin{array}{c}\mathrm{mol} \mathrm{C}_{7} \text { hydrocracked/100 } \\
\mathrm{mol} \mathrm{C}_{10} \text { hydrocracked }\end{array}$ & 0 & 1 & $3^{b}$ & 2 & $4^{b}$ & & $\mathrm{np}^{a}$ & $1^{b}$ \\
\hline R eference & (20) & (21) & (22) & (5) & (19) & & (19) & (5) \\
\hline
\end{tabular}

N ote. A t a $\% n-C_{10}$ hydroconversion the catalysts hydrocrack a certain percentage of the feed ( $\% \mathrm{C}_{10}$ hydrocracked), and they yield a percentage branched isomers in the secondary hydrocracking product slate $\left({ }^{1} / 5 \cdot \sum_{x=4}^{7} \% i\right.$ - $\mathrm{C}_{x}$, with $\%$ $i$ - $C_{x}$ the percentage of $i-C_{x}$ in each of the the four $C_{x}$ fractions, and divided by five to account for the intrinsically linear $C_{3}$ fraction) and in the $C_{5}$ fraction ( $\left.\% i-C_{5}\right)$. A s only heptane $\left(C_{7}\right)$ isomers are liable to secondary hydrocracking ( 21 , 39,51 ) the extent of secondary hydrocracking is referred to as " mol $C_{7}$ hydrocracked/100 mol $C_{10}$ hydrocracked." It was calculated by halving the difference between the molar $C_{3}$ and $C_{7}$ yield per 100 mol of hydrocracked decane $\left(C_{10}\right)$. The $n-\mathrm{C}_{10}$ hydroconversion catalysts that we discuss were loaded with either $0.5(19,20)$ or 1.0 wt\% Pt $(5,21,22,23)$. For comparison, the $n-C_{7}$ hydroconversion catalysts were loaded with $0.4 \mathrm{wt} \% \mathrm{Pt}(8)$.

${ }^{a}$ np, not published.

${ }^{b}$ E stimated graphically.

Criteria for identifying mass transport or hydrogenation rate limitations. The intrinsic shape-selective properties of zeolites can be compared only when the acid-catalyzed reactions inside the zeolite pores determines the overall paraffin hydroconversion rate (10), i.e., in the absence of premature hydrocracking due to mass transfer or hydrogenation rate limitations. In principle, it should be straightforward to identify M FI- and MEL-type zeolite catalysts in which the acid catalysis step determines the paraffin hydroconversion rate, for these catalysts characteristically (i) yield a primary (i.e., before secondary reactions) hydrocracking product slate consisting of equal amounts of linear and branched paraffins (E q. [4]), (ii) yield a primary $C_{7}$ fraction consisting exclusively of $i-C_{7}$ (Eq. [4]), (iii) yield a primary $C_{5}$ fraction consisting of equal amounts of $n-C_{5}$ and $i-C_{5}$ (E q. [4]), and (iv) have a low (primary and secondary) hydrocracking selectivity $(10,41-43)$. In practice, consecutive hydrocracking and hydroisomerization yield a secondary product slate interfering with a straightforward identification (19). The primary $i-C_{7}$ isomers are particularly prone to consecutive reactions, because they are the most reactive $(37,39,51)$ and because they will stay adsorbed longer than the other primary hydrocracking products will (52). B y contrast, the $C_{5}$ isomers are relatively unreactive $(37,39,51)$ and are short enough to desorb rapidly (and stay desorbed) due to competitive adsorption with longer molecules (52). Thus, of the four criteria a $C_{5}$ fraction consisting of equal amounts of $n-C_{5}$ and $i-C_{5}$ (iii) and a low hydrocracking selectivity (iv) are the least affected by secondary reactions, and therefore are the most straightforward criteria for identifying M FI - and MEL-type zeolite catalysts in which the acid catalysis step determines the paraffin hydroconversion rate.

$M$ ass transport or hydrogenation rate limitations. A n examination of the published $n-\mathrm{C}_{10}$ hydroconversion data (Table $1(5,19-22)$ ) shows that only one paper (19) discusses an M FI-type zeolite catalyst that yields a secondary hydrocracking product slate with a $\mathrm{C}_{5}$ fraction consisting of close to $50 \% \quad i-\mathrm{C}_{5}$. A t $46 \% n-\mathrm{C}_{10}$ hydroconversion, this catalyst loses only $7 \%$ of the $\mathrm{C}_{10}$ feed through hydrocracking ( $\% \mathrm{C}_{10}$ hydrocracked, Table 1 ), whereas at that same conversion level the other catalysts lose more than $35 \%$ of the $\mathrm{C}_{10}$ feed $(5,20-22)$. This low primary hydrocracking selectivity, the small amount of secondary hydrocracking ( $m o l ~ C_{7}$ hydrocracked/100 mol $C_{10}$ hydrocracked) at a high \% $n-\mathrm{C}_{10}$ hydroconversion, and the high percentage of branched paraffins in the secondary hydrocracking product slate $\left(1 / 5 \sum_{x=4}^{7} \% \quad i-C_{x}\right)$ (Table 1 , also explains formula) all indicate that this particular MFI-type zeolite catalyst 
exhibits minimal mass transport and hydrogenation rate limitations (10, 41-43). The other tabulated M FI-type zeolite catalysts yield significantly less than $50 \% i-C_{5}$ and have a high hydrocracking selectivity (Table 1 ). This is characteristic for hydroconversion dominated by the mass transport or hydrogenation rate and not by the acid-catalyzed reactions. They employ crystals that are to o large, have too high an acid site density, or are operated at such a low hydrogen partial pressure $(41,50)$ that the $C_{10}$ mass transport rate between the acid sites inside the crystals and the (de-) hydrogenation sites at the crystal's surface (10) is rate limiting $(38,43)$. Remarkably, also very small M FI-type zeolite crystals cluttered with amorphous debris from a prematurely aborted zeolite synthesis exhibit the high hydrocracking selectivity (4-5\% $C_{10}$ hydrocracked at 8-9\% conversion (23), cf. Table 1) that is characteristic for mass transport or hydrogenation rate limitations. The preponderance of studies on Pt-loaded M FI-type zeolite catalysts in which the $n-C_{10}$ hydroconversion rate was not dominated by the acid catalyzed reactions could explain why the premature $i-\mathrm{C}_{10}$ hydrocracking used to be considered so important $(5,10,19,22)$.

In addition to an MFI-type zeolite catalyst, there is a MEL-type zeolite catalyst for which $n-C_{10}$ hydroconversion data have been published that meets the percentage $i-\mathrm{C}_{5}$ criterion and that shows a low hydrocracking selectivity (Table 1 ), indicating that intracrystalline acid catalyzed reactions determine the $n-C_{10}$ hydroconversion rate (5). This MEL-type zeolite catalyst does not suffer from mass transport limitations, even under conditions where an equivalent M FI-type zeolite does (5) (Table 1). When comparing the two catalysts without mass transport limitations $(5,19)$, the MEL-type zeolite hydroisomerizes a higher percentage of the feed than the MFI-type zeolite catalyst (Table 1). B oth the higher threshold for mass transport limitations and the higher hydroisomerization selectivity of the MEL-type zeolite indicate that branched $C_{10}$ isomers have a lower chance for being converted when they are inside MEL-type pores than when they are inside M FItype pores. This implies that the MEL-type zeolite either has an intrinsically lower consecutive-reaction rate or an intrinsically higher $\mathrm{C}_{10}$ diffusion rate than the $\mathrm{MFI}$-type zeolite. So far there is no indication of a major difference in $n-\mathrm{C}_{10}$ or $i-\mathrm{C}_{10}$ diffusion rate between M E L - and M FI-type zeolites (13) suggesting that the difference must lie in the consecutive-reaction rate (5).

Primary hydrocracking product slates. R econstruction of the primary hydrocracking product slates from the secondary hydrocracking product slates sheds some light on the different reactions that follow the formation of $i-C_{10}$. A s discussed above, the composition of the $C_{5}$ fraction will be the same in both the primary and the secondary hydrocracking product slate, but all other product fractions require reconstruction. The effects of secondary ii- $C_{7}$ hydro- cracking can be eliminated by adding one ii- $\mathrm{C}_{7}$ molecule to the $C_{7}$ fraction for each set of one $i-C_{4}$ molecule and $C_{3}$ molecule removed from their respective product fractions until there are equal amounts of $C_{3}$ and $C_{7}$. This yields the primary $\mathrm{C}_{3}$ fraction. The resultant $\mathrm{C}_{4}$ fraction is representative for the primary $\mathrm{C}_{4}$ fraction as well, for secondary hydroisomerization of $\mathrm{C}_{4}$ is unlikely. The effects of secondary hydroisomerization on the resultant $C_{7}$ fraction can be eliminated, because the hydrocracking mechanism stipulates that the primary $\mathrm{C}_{7}$ fraction consists $100 \%$ of $i-C_{7}$. A pplying this procedure to the secondary hydrocracking product slate of the ME L-type zeolite (Fig. $2 \mathrm{~B}$ ) yields virtually complete primary $i-\mathrm{C}_{4} / n-\mathrm{C}_{6}$ and $i-\mathrm{C}_{6} / n-\mathrm{C}_{4}$ product pairs (Fig. 2D), indicating that the $\mathrm{C}_{6}$ fraction has remained relatively unaffected by secondary reactions. Construction of a secondary hydrocracking product slate of the M FI-type zeolite based on the published data (19) (Fig. 2A) requires making the assumption that the composition of the carbon number fractions does not drastically change when the conversion is increased from 46 to $93 \% n-C_{10}$ conversion. If we apply our procedure to turn this secondary hydrocracking product slate into a primary one (Fig. $2 \mathrm{C}$ ), the $\mathrm{C}_{6}$ fraction contains $10 \%$ too much $i-\mathrm{C}_{6}$ to complete the primary $i-\mathrm{C}_{4} / n-\mathrm{C}_{6}$ and $i-\mathrm{C}_{6} / n-\mathrm{C}_{4}$ product pairs. Therefore, $i-\mathrm{C}_{6}$ and $i-\mathrm{C}_{4}$ data are within the tabulated $15 \%$ error margin (Table 2).

Experimental $\mathrm{ii}-\mathrm{C}_{10}$ selectivity. On the basis of the hydrocracking mechanism $(39,44,45)$ (Figs. 3-5), it is possible to link the individual components of the primary $C_{10}$ hydrocracking product slate (Table 2; Figs. $2 \mathrm{C}$ and $2 \mathrm{D}$ ) to their ii- $\mathrm{C}_{10}$ precursors through four linear equations. $\mathrm{E}$ ach $100 \mathrm{~mol}$ of $\mathrm{ii}-\mathrm{C}_{10}$ consists of $\left[n, m-\mathrm{DiM} \mathrm{e}-\mathrm{C}_{8}\right] \mathrm{mol}$ of $n, m-$ dimethyl octane and hydrocrack into a known number of moles of branched isomers $\left[i-C_{x}\right]$. W ith these definitions in place, the individual hydrocracking reactions (Figs. 3 and 5) can be described as:

$$
\begin{aligned}
& {\left[2,2-\mathrm{D} \mathrm{iM} \mathrm{e}-\mathrm{C}_{8}\right]+u \cdot\left[2,4-\mathrm{D} \mathrm{iM} \mathrm{e}-\mathrm{C}_{8}\right]=\left[i-\mathrm{C}_{4}\right]} \\
& {\left[3,3-\mathrm{D} \mathrm{iM} \mathrm{e-} \mathrm{C}_{8}\right]+v \cdot\left[3,5-\mathrm{D} \mathrm{iM} \mathrm{e-} \mathrm{C}_{8}\right]=\left[i-\mathrm{C}_{5}\right]} \\
& w \cdot\left[4,4-\mathrm{D} \mathrm{iM} \mathrm{e}_{8}\right]+(1-v)\left[3,5-\mathrm{D} \mathrm{iM} \mathrm{e-} \mathrm{C}_{8}\right]=\left[i-\mathrm{C}_{6}\right] \\
& (1-w) \cdot[4,4-\mathrm{D} \mathrm{iM} \mathrm{e-C}]+(1-u)\left[2,4-\mathrm{D} \mathrm{iM} \mathrm{e-C_{8 }}\right]=\left[i-\mathrm{C}_{7}\right] \text {. }
\end{aligned}
$$

In these equations $\mathrm{u}, v$, and $w$ are the probabilities that 2,4-, 3,5-, and 4,4-DiM e- $C_{8}$ split off either a small $(u, v, w>0.5)$ or a long $(u, v, w<0.5)$ iso-paraffin. A ssuming that the ii- $\mathrm{C}_{10}$ precursors have no strong preference for splitting either way ( $u \approx v \approx w \approx 0.5$ ) the solutions for the above four equations severely limit the possible ii- $\mathrm{C}_{10}$ hydrocracking precursors (Table 2).

In summary, a scrutiny of the published $n-\mathrm{C}_{10}$ hydroconversion data shows that of the two kinetically favored ii$\mathrm{C}_{10}$ molecules (Fig. 4), the M FI-type zeolite predominantly 
A

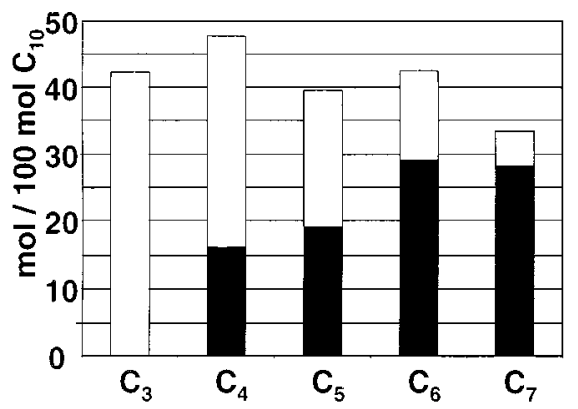

C

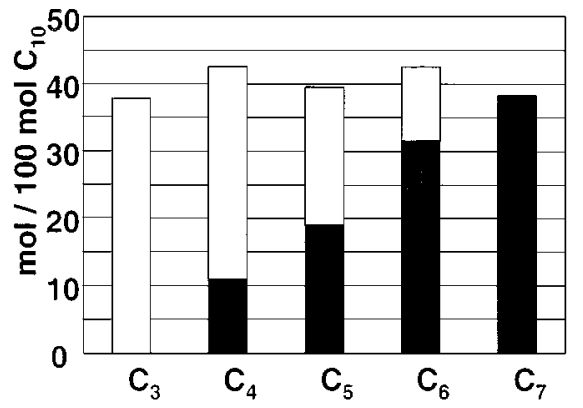

B

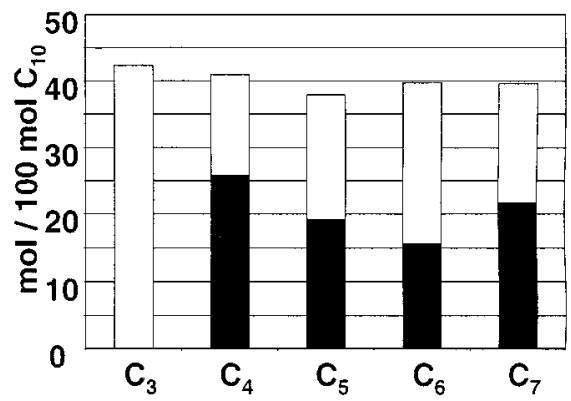

D

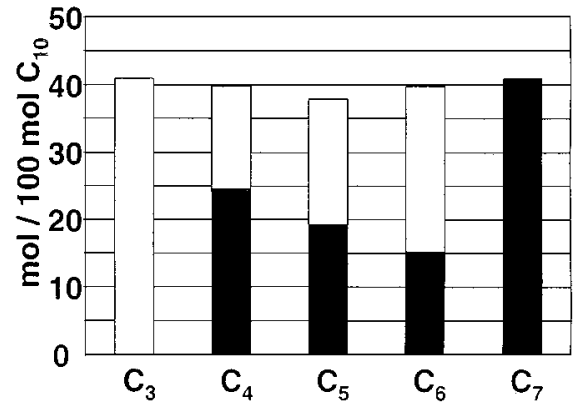

FIG. 2. The secondary $(A$ and $B)$ and primary $(C$ and $D)$ hydrocracking product slates of the $M F I(A$ and $C$ ) and the $M E L$-type zeolites ( $B$ and D) at 46 and $49 \% n$ - $C_{10}$ hydroconversion respectively $(5,19)$ : normal $(\square)$ and branched $(\square)$ isomer yield.

hydrocracks the geminal ii- $\mathrm{C}_{10}\left(4,4-\mathrm{D}\right.$ iM e- $\left.\mathrm{C}_{8}\right)$, whereas the MEL-type zeolite predominantly hydrocracks the quasivicinal ii- $\mathrm{C}_{10}\left(2,4-\mathrm{D} \mathrm{iM} \mathrm{eC}_{8}\right)$ (Table 2$)$. We can now turn to the free energies of formation as amenable by molecular simulations to see why there is such a marked difference in intrinsic shape selectivity.

TABLE 2

The Branched Primary Hydrocracking Products ( $\left[i-\mathrm{C}_{x}\right]$ ( $\mathrm{mol} / \mathbf{1 0 0} \mathrm{mol} n, m$-D iMe-C 8 H ydrocracked)) from the MFIand ME L-Type Zeolites $(4,19)$ and Their D imethyl Octane Precursors ( $\left[n, m-D i M e-C_{8}\right](m o l \%)$ with Methyl Positions $n$ and $m$ ) Assuming No Preferential Hydrocracking into Small or Large $i-\mathrm{C}_{x}$

\begin{tabular}{lcc}
\hline & $M F I$ & $M E L$ \\
\hline Products & $15-11^{a}$ & \\
{$\left[i-C_{4}\right]$} & 19 & 26 \\
{$\left[i-C_{5}\right]$} & $28-32^{a}$ & 19 \\
{$\left[i-C_{6}\right]$} & 38 & 16 \\
{$\left[i-C_{7}\right]$} & & 40 \\
Precursors & $0-5^{b}$ & \\
{$\left[2,2-D\right.$ iM e- $\left.C_{8}\right]$} & $14-19$ & $0-2^{b}$ \\
{$[3,3-D$ iM e-C $]$} & $46-64$ & $17-19$ \\
{$\left[4,4-\right.$ D iM e- $\left.C_{8}\right]$} & $30-12$ & $28-31$ \\
{$\left[2,4-\right.$ D iM e- $\left.C_{8}\right]$} & $10-0$ & $52-48$ \\
{$\left[3,5-D\right.$ iM e- $\left.C_{8}\right]$} & & $4-0$ \\
\hline
\end{tabular}

${ }^{a}$ The mass balance dictates that $\left[i-\mathrm{C}_{7}\right]+\left[i-\mathrm{C}_{6}\right]+\left[i-\mathrm{C}_{5}\right]+$ $\left[i-\mathrm{C}_{4}\right]=100 \mathrm{~mol} / 100 \mathrm{~mol} \mathrm{C}_{10}$ hydrocracked.

${ }^{b}\left[n, m-\mathrm{DiM} \mathrm{e}-\mathrm{C}_{8}\right]$ is in $\mathrm{mol} \%$, so that the individual values should add up to $100 \mathrm{~mol} \%$.
Simulated ii- $\mathrm{C}_{10}$ selectivity. The free energy of formation of the individual ii- $\mathrm{C}_{10}$ hydrocracking precursors inside the MFI- and MEL-type zeolites shed some light on the postulated differences in hydrocracking precursors. A s indicated by a lower free energy of formation, MFI-type
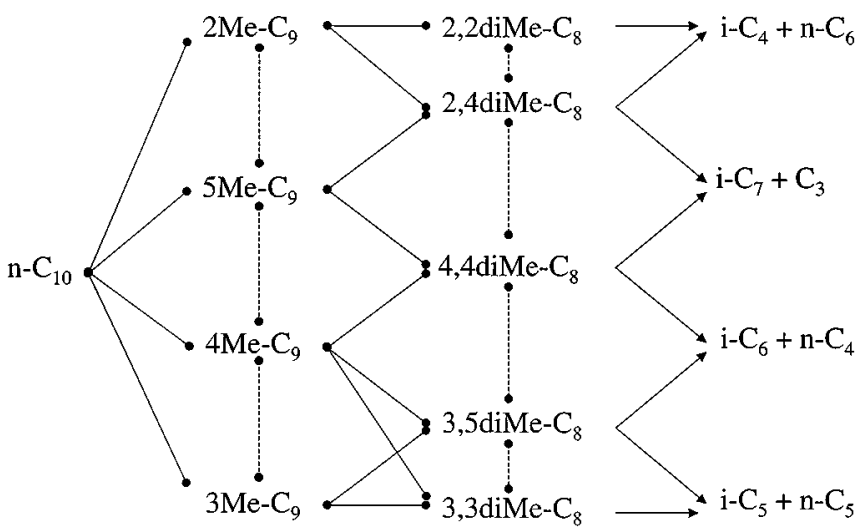

FIG. 3. O verview of the $n-C_{10}$ hydroconversion (19, 39): equilibration between isomers with $(-\mathbf{-})$ or without $(--)$ a change in the degree of branching and hydrocracking $(\rightarrow)$. Of all the ii- $\mathrm{C}_{10}$ isomers, only those with geminal or quasi-vicinal methyl groups are shown. The ii- $C_{10}$ isomers with neither geminal nor quasi-vicinal methyl groups hydrocrack $\sim 10^{2}$ times more slowly than the isomers shown $(46,47)$. This leaves them ample time to hydroisomerize into ii- $\mathrm{C}_{10}$ isomers with geminal or quasi-vicinal methyl groups, for their hydroisomerization rate is $\sim 10^{3}$ times faster than their hydrocracking rate (46). A ccordingly, the hydrocracking will be dominated by the $\mathrm{ii}-\mathrm{C}_{10}$ isomers with geminal or quasi-vicinal methyl groups that are shown. Figures 4 and 5 elucidate the individual hydroisomerization and hydrocracking reactions. 

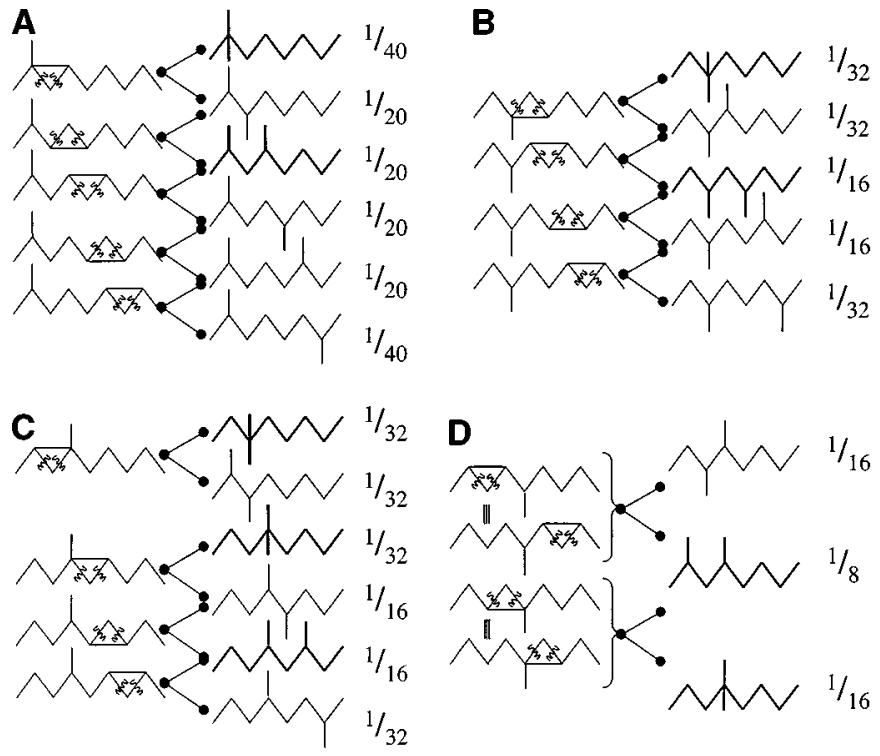

FIG. 4. The (protonated) cyclopropyl transition state ( $\nabla$ and $\Delta$ ) and the products for the hydroisomerization of $i-\mathrm{C}_{10}$ into ii- $\mathrm{C}_{10}$. (A) 2 Me- $\mathrm{C}_{9}$ hydroisomerization into 2,2-, 2,3-, 2,4-, 2,5-, 2,6-, 2,7-D iM e- $\mathrm{C}_{8}$; (B) 3-M e- $\mathrm{C}_{9}$ into 3,3-, 3,4-, 3,5-, 3,6-, 2,6-D iM e- $\mathrm{C}_{8}$; (C) 4-M e- $\mathrm{C}_{9}$ into 3,3-, 2,3-, 4,4-, 4,5-, 3,5-, 2,5-D iM e- $\mathrm{C}_{8}$; (D) 5-M e- $\mathrm{C}_{9}$ into 3,4-, 2,4-, 4,4-D iM e$\mathrm{C}_{8}$ (39). H ydrocracking precursors are shown in bold. The probabilities of formation of the isomers are given, assuming no preferential formation for any $i-\mathrm{C}_{10}$ isomer or transition state. The shape selectivity imposed by the ME L - and M FI-type zeolites shifts the probability toward the ii- $\mathrm{C}_{10}$ and $i$ $\mathrm{C}_{10}$ isomers that have a shape commensurate with the $\mathrm{M} \mathrm{EL}$ - and $\mathrm{M} \mathrm{FI-type}$ pores (12). Of the paraffins with geminal methyl groups, 4,4-D iM e- $\mathrm{C}_{8}$ has the highest chance of formation, of the paraffins with quasi-vicinal methyl groups, 2,4-D iM e- $\mathrm{C}_{8}$ is favored. The probability of 4,4- and 2,4-D iM e- $\mathrm{C}_{8}$ formation is further increased, because $5-\mathrm{M} \mathrm{e}-\mathrm{C}_{9}$ appears to be the $i-\mathrm{C}_{10}$ isomer preferentially retained $(13,32)$ and formed (Fig. 7; Table 5) by both MEL- and M FI-type zeolites.

zeolites preferentially form geminal ii- $C_{10}$, whereas M E L type zeolites preferentially form quasi-vicinal ii- $\mathrm{C}_{10}$ (Table 3). The reason for this selective decrease in free energy (Table 3) is that the shape of the M FI-type intersec-

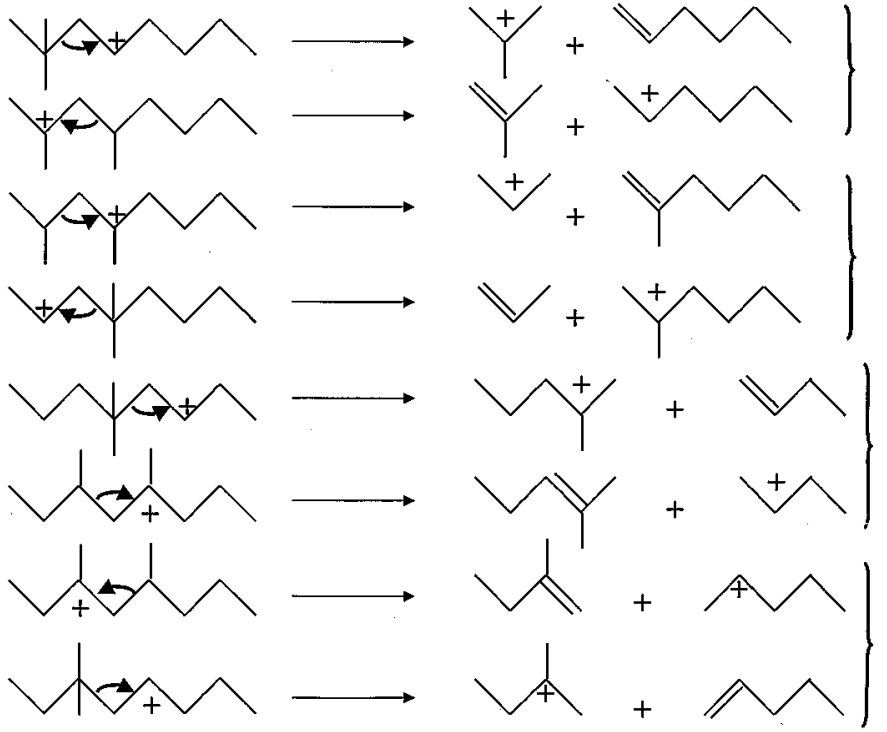

FIG . 5. Transitions states and intermediates for the hydrocracking of $\mathrm{ii}-\mathrm{C}_{10}$ isomers with geminal or quasi-vicinal methyl groups (19). A s all carbo-cationic and olefinic intermediates leave the catalysts as paraffins, carbo-cations and olefins with the same carbon backbone will end up as identical products, and are grouped together as such.

tion (Fig. $1 \mathrm{~A}$ ) is commensurate with that of geminal $\mathrm{ii}-\mathrm{C}_{10}$, whereas the shape of the larger MEL-type intersection (Fig. 1B) is commensurate with that of quasi-vicinal ii- $\mathrm{C}_{10}$ (Fig. 6). Thus, the intersections constitute a mold for the formation of particular hydrocracking precursors. Once formed, the hydrocracking precursors will be trapped at the intersections, for they diffuse too slowly $(12,31)$ to leave the pores intact. The preference of M FI-type zeolites for geminal instead of quasi-vicinal ii- $\mathrm{C}_{10}$ becomes more evident when the temperature is increased from 415 to $523 \mathrm{~K}$. Thus, the decreased free energy of formation of geminal ii- $\mathrm{C}_{10}$ inside $\mathrm{M} \mathrm{FI}$-type zeolites and of quasi-vicinal $\mathrm{ii}-\mathrm{C}_{10}$ inside MEL-type zeolites supports the empirical observation that there is an intrinsic difference in their

\section{TABLE 3}

G as Phase F ree E nergy of F ormation ( $\Delta G_{\text {gas }}^{\mathrm{f}}(\mathrm{kJ} / \mathrm{mol}$ ), from Literature (54) D ata), F ree E nergy of Adsorption $\left(\Delta G_{\text {ads }}(\mathrm{kJ} / \mathrm{mol})\right)$, Adsorption E nthalpy $\left(\Delta H_{\text {ads }}(\mathrm{kJ} / \mathrm{mol})\right)$, and F reeE nergy of F ormation I nsidea Z eolite $\left(\Delta G_{\text {sieve }}^{\mathrm{f}}\right.$ (kJ/mol)) for Decane I somers in MFI- or ME L-Type Silicas at $415 \mathrm{~K}$

\begin{tabular}{|c|c|c|c|c|c|c|c|}
\hline $\mathrm{C}_{10}$ isomer & $\begin{array}{c}\Delta G_{\text {gas }}^{\mathrm{f}} \\
(\mathrm{kJ} / \mathrm{mol})\end{array}$ & $\begin{array}{c}\text { M FI } \Delta G_{\text {ads }} \\
(\mathrm{kJ} / \mathrm{mol})\end{array}$ & $\begin{array}{c}\text { MEL } \Delta G_{\text {ads }} \\
(\mathrm{kJ} / \mathrm{mol})\end{array}$ & $\begin{array}{c}\mathrm{MFI} \Delta H_{\mathrm{ads}} \\
(\mathrm{kJ} / \mathrm{mol})\end{array}$ & $\begin{array}{c}\mathrm{MEL} \Delta H_{\mathrm{ads}} \\
(\mathrm{kJ} / \mathrm{mol})\end{array}$ & $\begin{array}{l}\text { M FI } \Delta G_{\text {sieve }}^{\mathrm{f}} \\
(\mathrm{kJ} / \mathrm{mol})\end{array}$ & $\begin{array}{c}\text { MEL } \Delta G_{\text {sieve }}^{\mathrm{f}} \\
(\mathrm{kJ} / \mathrm{mol})\end{array}$ \\
\hline$n-\mathrm{C}_{10}$ & 150 & -54 & -49 & -113 & -112 & 96 & 101 \\
\hline $2-\mathrm{M} \mathrm{e}-\mathrm{C}_{9}$ & 147 & -53 & -47 & -112 & -108 & 94 & 99 \\
\hline $5-\mathrm{M} \mathrm{e}-\mathrm{C}_{9}$ & 150 & -53 & -52 & -115 & -113 & 96 & 98 \\
\hline 2,2-D iM e-C 8 & 145 & -48 & -38 & -105 & -100 & 98 & 107 \\
\hline $3,3-\mathrm{D} \mathrm{iM} \mathrm{e}^{-\mathrm{C}_{8}}$ & 147 & -46 & -37 & -102 & -97 & 101 & 110 \\
\hline $4,4-\mathrm{D} \mathrm{iM} \mathrm{e}^{-\mathrm{C}_{8}}$ & 147 & -50 & -39 & -106 & -99 & 97 & 108 \\
\hline $2,4-\mathrm{D} \mathrm{iM} \mathrm{e}^{-\mathrm{C}_{8}}$ & 150 & -42 & -55 & -114 & -117 & 108 & 96 \\
\hline 3,5-D iM e- $\mathrm{C}_{8}$ & 147 & -37 & -52 & -106 & -114 & 111 & 96 \\
\hline $3,3,5-$ TriM e-C 7 & 154 & -20 & -22 & -76 & -91 & 134 & 132 \\
\hline
\end{tabular}



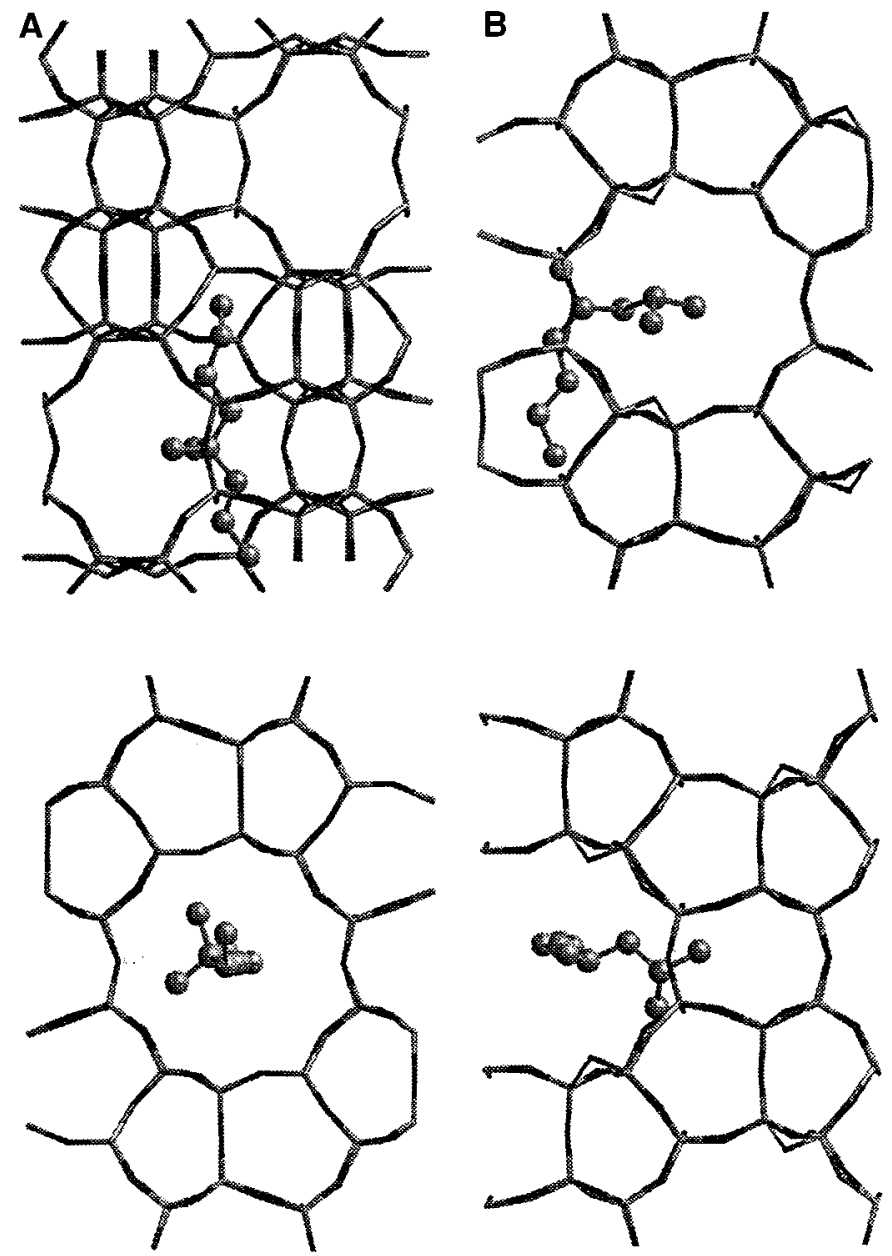

FIG. 6. Schematic drawing of the thermodynamically preferred positions of (A) 4,4-diM e- $C_{8}$ inside M FI-type zeolite, with octyl group in the straight channel and the methyl groups protruding into the sinusoidal channel, (B) 2,4-diM e- $C_{8}$ inside $M E L$-type zeolite, with a hexyl group in one straight channel and an iso-butyl group protruding into another straight channel. Paraffins are shown as ball-and-stick models, frameworks as sticks only. Top and bottom views are at a $90^{\circ}$ angle from each other.

hydrocracking functionality and offers an explanation of why that is so.

Simulated ii- $C_{7}$ selectivity. The adsorption properties of ii- $\mathrm{C}_{7}$ hydrocracking precursors (Table 4 ) are analogous to those of $\mathrm{ii}^{-\mathrm{C}_{10}}$ (Table 3). A gain M FI-type zeolites lower the free energy of formation of $\mathrm{ii}-\mathrm{C}_{7}$ with geminal methyl groups and MEL-type zeolites lower that of the ii- $C_{7}$ with quasi-vicinal methyl groups (viz. 2,4-dimethyl pentane). Since $n-C_{10}$ and $n-C_{7}$ hydroconversion are

TABLE 4

G as Phase F ree E nergy of F ormation ( $\Delta G_{\text {gas }}^{\mathrm{f}}(\mathrm{kJ} / \mathrm{mol})$, from Literature $D$ ata (54)), Change of F ree $E$ nergy of Formation by Zeolite $\left(\Delta G_{\text {ads }}(\mathrm{kJ} / \mathrm{mol})\right)$, Adsorption Enthalpy $\left(\Delta H_{\text {ads }}(\mathrm{kJ} / \mathrm{mol})\right)$, and Free Energy of Formation Inside a Zeolite $\left(\Delta G_{\text {sieve }}^{\mathrm{f}}(\mathrm{kJ} / \mathrm{mol})\right)$ for Heptane I somers in MFI- or ME L-Type Silicas at $523 \mathrm{~K}$

\begin{tabular}{|c|c|c|c|c|c|c|c|}
\hline $\mathrm{C}_{7}$ isomer & $\begin{array}{c}\Delta G_{\text {gas }}^{\mathrm{f}} \\
(\mathrm{kJ} / \mathrm{mol})\end{array}$ & $\begin{array}{c}\mathrm{MFI} \Delta G_{\text {ads }} \\
(\mathrm{kJ} / \mathrm{mol})\end{array}$ & $\begin{array}{c}\text { MEL } \Delta G_{\text {ads }} \\
(\mathrm{kJ} / \mathrm{mol})\end{array}$ & $\begin{array}{c}\mathrm{MFI} \Delta H_{\mathrm{ads}} \\
(\mathrm{kJ} / \mathrm{mol})\end{array}$ & $\begin{array}{c}\mathrm{MEL} \Delta H_{\text {ads }} \\
(\mathrm{kJ} / \mathrm{mol})\end{array}$ & $\begin{array}{l}\mathrm{MFI} \Delta G_{\text {sieve }}^{\mathrm{f}} \\
(\mathrm{kJ} / \mathrm{mol})\end{array}$ & $\begin{array}{l}\mathrm{MEL} \Delta G_{\text {sieve }}^{\mathrm{f}} \\
\quad(\mathrm{kJ} / \mathrm{mol})\end{array}$ \\
\hline $\begin{array}{l}n-\mathrm{C}_{7} \\
2-\mathrm{Me} \mathrm{e} \mathrm{C}_{6} \\
3-\mathrm{Me} \text { - } \mathrm{C}_{6}\end{array}$ & $\begin{array}{l}167 \\
164 \\
164\end{array}$ & $\begin{array}{l}-27 \\
-27 \\
-26\end{array}$ & $\begin{array}{l}-24 \\
-25 \\
-24\end{array}$ & $\begin{array}{l}-78 \\
-80 \\
-78\end{array}$ & $\begin{array}{l}-76 \\
-79 \\
-77\end{array}$ & $\begin{array}{l}140 \\
137 \\
138\end{array}$ & $\begin{array}{l}143 \\
140 \\
140\end{array}$ \\
\hline $\begin{array}{l}2,2-\text { diM e- } C_{5} \\
\text { 3,3-diM e-C } C_{5} \\
\text { 2,4-diM e-C } C_{5}\end{array}$ & $\begin{array}{l}167 \\
168 \\
169\end{array}$ & $\begin{array}{l}-24 \\
-18 \\
-13\end{array}$ & $\begin{array}{r}-14 \\
-8 \\
-27\end{array}$ & $\begin{array}{l}-74 \\
-68 \\
-73\end{array}$ & $\begin{array}{l}-67 \\
-62 \\
-82\end{array}$ & $\begin{array}{l}143 \\
150 \\
156\end{array}$ & $\begin{array}{l}153 \\
160 \\
142\end{array}$ \\
\hline $2,3-\operatorname{diM}$ e- $\mathrm{C}_{5}$ & 163 & -25 & -20 & -78 & -76 & 138 & 143 \\
\hline
\end{tabular}



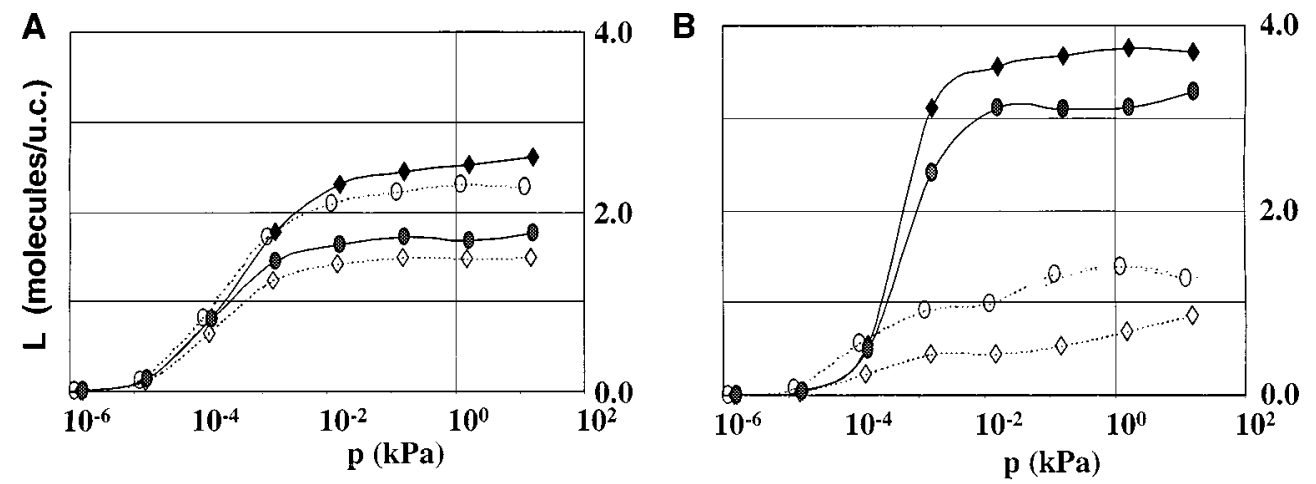

FIG. 7. The adsorption isotherm at $415 \mathrm{~K}$ as calculated by CBMC calculations of a binary mixture of $50 \%$ 2-methyl nonane (-- $\diamond--)$ and $50 \%$ $n$-decane (- - ), and of 50\% 5-methyl nonane (--O- -) and 50\% n-decane (- - ). (A) M FI-type and (B) ME L-type silica.

analogous, we would expect that MFI-type zeolites preferentially hydrocrack geminal ii- $C_{7}$, whereas $M E L$-type zeolites prefer the quasi-vicinal $\mathrm{ii} \mathrm{C}_{7}$. U nfortunately this difference in the hydrocracking pathway is difficult to quantify, as the individual $\mathrm{ii}^{-\mathrm{C}_{7}}$ precursors do not leave their signature in the $\mathrm{C}_{7}$ hydrocracking product slate (E q. [3]).

ii- $\mathrm{C}_{10}$ versus ii- $\mathrm{C}_{7}$ hydrocracking. The difference in hydrocracking pathway between the M FI - and ME L -type zeolite can explain why an MFI-type zeolite hydrocracks a higher percentage of $C_{10}$ feed but not of $C_{7}$ feed. $K$ inetic data show that at low temperatures (below $460-500 \mathrm{~K}$ for a $C_{8}$ feed) the geminal di-methyl paraffins preferred by the M FI-type zeolite have the highest hydrocracking rate, whereas at higher temperature (above $460-500 \mathrm{~K}$ for a $\mathrm{C}_{8}$ feed) the quasi-vicinal di-methyl paraffins preferred by the M E L -type zeolite have the highest hydrocracking rate (47, 48). Since zeolites that hydrocrack paraffins at a higher rate will also hydrocrack a larger percentage of the feed, this can explain why M FI-type zeolites (at 400,440 , or $520 \mathrm{~K}$ ) hydrocrack more $C_{10}$ than MEL-type zeolites (at $430 \mathrm{~K}$ ) (Table 1), but not more $\mathrm{C}_{7}$ (all comparative tests at $523 \mathrm{~K}$ (8)). A Ithough the low $C_{10}$ and high $C_{7}$ hydroconversion test temperature can explain the low $\mathrm{C}_{10}$ and high $\mathrm{C}_{7}$ hydrocracking selectivity of the MEL-type zeolite, it fails to explain why MEL-type zeolites reportedly have lower hydrocracking selectivity than M FI-type zeolites at temperatures as high as $655 \mathrm{~K}(6)$.
Simulated competitive adsorption. A n alternative explanation for the differences in paraffin hydrocracking between MFI- and MEL-type zeolites follows from the dramatic selectivity difference that shows up in a study on the adsorption from mixtures of equal amounts of gaseous $n-\mathrm{C}_{10}$ and $i-\mathrm{C}_{10}$. Both at low loading (Table 3 ) and at high loading (Fig. 7A), M FI-type zeolites adsorb $n-\mathrm{C}_{10}$ or $i-C_{10}$ in approximately equal amounts, indicating that molecule-molecule interactions have only a minor effect on the free energy of adsorption ( $\sim 1 \mathrm{~kJ} / \mathrm{mol}$ change) in M FI-type zeolites. In marked contrast, M E L -type zeolites devel op a strong preference for linear paraffins at high loading (Fig. 7B). This preference corresponds to a decrease in the free energy of the adsorption (and of formation) of $n-\mathrm{C}_{10}$ relative to that of $i-\mathrm{C}_{10}$ of $4-5 \mathrm{~kJ} / \mathrm{mol}$ (Table 5 ). A probable cause for the decrease in free energy of the linear paraffins relative to that of the branched paraffins is that the former can fill the pores with a higher packing efficiency (retaining a higher entropy) than the latter (cf. 24, 53). Closer inspection of the molecules shows that roughly half of the four M FI-type intersections per unit cell contain $i-\mathrm{C}_{10}$ molecules, whereas slightly fewer than half of the two large ME L-type intersections per unit cell still contain $i-\mathrm{C}_{10}$ at full loading. CBM C calculations indicate that full loading is obtained at $20 \mathrm{kPa} \mathrm{C}_{10}$ at temperatures up to $570 \mathrm{~K}$ and above $1 \mathrm{kPaC}_{10}$ at temperaturesnear $415 \mathrm{~K}$, i.e., at the $n-\mathrm{C}_{10}$ hydroconversion conditions discussed here (Table 1).

\section{TABLE 5}

E ffect of Intermolecular Interactions on the Difference in the F ree Energy of A dsorption between $i$ - $C_{10}$ and $n-C_{10}\left(\Delta G_{\text {ads } i}-\Delta G_{\text {ads } n}(\mathrm{~kJ} / \mathrm{mol})\right)$

\begin{tabular}{ccccc}
\hline M Fl empty & M Fl full & MEL empty & M L full \\
$i-C_{10}$ isomer & $\begin{array}{c}\Delta G_{\text {ads } i}-\Delta G_{\text {ads } n} \\
(\mathrm{~kJ} / \mathrm{mol})\end{array}$ & $\begin{array}{c}\Delta G_{\text {ads } i}-\Delta G_{\text {ads } n} \\
(\mathrm{~kJ} / \mathrm{mol})\end{array}$ & $\begin{array}{c}\Delta G_{\text {ads } i}-\Delta G_{\text {ads } n} \\
(\mathrm{~kJ} / \mathrm{mol})\end{array}$ & $\begin{array}{c}\Delta G_{\text {ads } i}-\Delta G_{\text {ads } n} \\
(\mathrm{~kJ} / \mathrm{mol})\end{array}$ \\
\hline 2-M e- $\mathrm{C}_{9}$ & 0.8 & 1.8 & 1.7 & 5.7 \\
5-M e-C & 0.4 & -0.9 & -2.5 & 2.9 \\
\hline
\end{tabular}



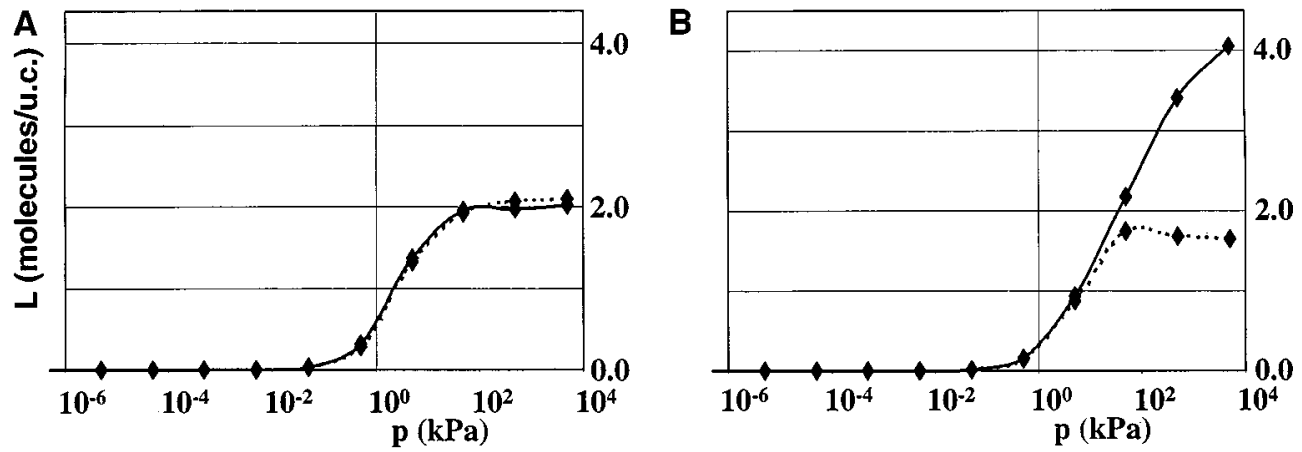

FIG . 8. The adsorption isotherm at $523 \mathrm{~K}$ as calculated by CBMC calculations of a binary mixture of $50 \% 2-$ methyl hexane (-- $\bullet-$-) and $50 \%$ $n$-heptane (- -). (A) M FI-type and (B) M E L -type silica.

Competitive adsorption in $n-\mathrm{C}_{10}$ hydroconversion. A t full loading, molecule-molecule interactions impede formation of $i-C_{10}$ out of $n-C_{10}$ by increasing the free energy of formation of the former at the large MEL-type intersections. In addition, they impede hydroisomerization reactions following the formation of $i-\mathrm{C}_{10}$ by facilitating the (re-)adsorbtion of $n-C_{10}$ at the cost of the (re-)adsorption of $i$ - $\mathrm{C}_{10}$. In M FI-type zeolites molecule-molecule interactions have no such marked effect (Tables 3 and 5 ). The formation of $i i-\mathrm{C}_{10}$ hydrocracking precursors from $i-\mathrm{C}_{10}$ by consecutive hydroisomerization reactions is further impeded by the limited availability of suitable sites in the M E L -type zeolites at full loading. There are only half as many large M E L -type intersections asthere are M F I-type intersections (Fig. 1). B oth the higher selectivity for absorbing linear instead of branched paraffins and the lower density of sites suitable for forming hydrocracking precursors will suppress consecutive hydrocracking reactions, and explain the lower hydrocracking selectivity (and higher hydroisomerization selectivity) of ME L -type zeolites.

No competitiveadsorption in $n-\mathrm{C}_{7}$ hydroconversion. Interestingly, the adsorption simulations not only explain why the M EL -type zeolite has a higher $n-\mathrm{C}_{10}$ hydroisomerization selectivity than the M FI-type zeolite, they also explain why this is not the case for the $n-C_{7}$ hydroisomerization (8) selectivity. The comparative $n-C_{7}$ hydroconversion tests where done at $10 \mathrm{kPa} n-\mathrm{C}_{7}, 523 \mathrm{~K}$ (8). A t this temperature and pressure $\mathrm{MFI}$ - and ME L -type zeolites have a low enough loading (about one molecule per unit cell) for $n-C_{7}$ and $i-C_{7}$ to have a comparable free energy of formation in both M FI- and MEL-type zeolites (Fig. 8). In addition, there is no shortage of available sites at the intersections of these zeolites to form hydrocracking precursors. Thus, the $n-C_{7}$ hydroconversion tests were done at too low a $C_{7}$ loading for competitive adsorption of $n-\mathrm{C}_{7}$ and $i-\mathrm{C}_{7}$ to occur and so demonstrate the intrinsic selectivity differences between M FI- and M E L-type zeolites.

A ctual hydrodewaxing tests. It is difficult to judge what the adsorption properties of MEL - and M FI-type zeolites are when a complex feedstock with paraffins significantly longer than $\mathrm{C}_{10}$ is converted at a temperature as high as $655 \mathrm{~K}$ (instead of the $430-523 \mathrm{~K}$ used for $C_{7}$ and $C_{10}$ ) (6). We are tempted to conclude that competitive adsorption between linear paraffins and branched paraffins will occur. In that case the lower density and lower accessibility of the large M E L -type intersections as compared to the M FI-type intersections will overrule the enhancement of the hydrocracking selectivity of M E L -type zeolite by the high operation temperature. To found such a conclusion more firmly would require more experimental studies quantifying the separate effects of temperature and loading on the paraffin hydroconversion selectivity of MEL- and MFI-type zeolites.

\section{CONCLUSIONS}

When the rate of the acid-catalyzed reactions determines the $n-\mathrm{C}_{10}$ hydroconversion rate, M FI- and M E L -type zeolites hydroisomerize normal paraffins into paraffins with geminal or quasi-vicinal methyl groups before they hydrocrack them. A $n$ analysis of the hydrocracking product slates and of the adsorption properties obtained by molecular simulations indicates that M FI-type zeolites intrinsically hydrocrack more geminal and fewer quasi-vicinal di-methyl paraffins than MEL-type zeolites. A s geminal di-methyl paraffins hydrocrack faster than quasi-vicinal di-methyl paraffins at low temperature, but not at high temperature, the selectivity for geminal di-methyl paraffins explains why M FI-type zeolites hydrocrack more of a $C_{10}$ feed than a ME L-type zeolite (selectivity tested at low temperature), but not more of a $C_{7}$ feed (tested at high temperature). The adsorption properties indicate that the higher selectivity of the M FI-type structure for adsorbing branched rather than linear paraffin reactants also contributes to its higher hydrocracking selectivity as compared to a M E L-type zeolite. As this higher reactant selectivity is only significant at sufficiently high loading, it also explains why M FI-type zeolites showed higher $n-C_{10}$ hydrocracking (tested at high loading), but not higher $n-C_{7}$ hydrocracking 
selectivity (tested at low loading) than a MEL-type zeolite.

\section{ACKNOWLEDGMENTS}

These investigations are supported in part by the Netherlands R esearch Counsil for Chemical Sciences (CW) with financial aid from the Netherlands Technology Foundation and by the Netherlands O rganization for Scientific R esearch (NWO) through PIO NIER. The authors wish to thank C. H. R oemkens, J. A . R. van Veen, W. H. J. Stork, A . L. M yers, H. Schenk, D. Frenkel, D. D ubbeldam, and M. S. R igutto for their comments on our manuscript.

\section{REFERENCES}

1. B lauwhoff, P. M. M ., G osselink, J. W., K ieffer, E . P., Sie, S. T., and Stork, W. H. J., in "Catalysis and Z eolites" ( J. Weitkamp and L. Puppe, E ds.), pp. 437-538. Springer, B erlin, 1999.

2. Chen, N. Y., G arwood, W. E., and D wyer, F. G., "Shape Selective Catalysis in Industrial A pplications," pp. 38-83. Dekker, New York, 1996.

3. Free, H. W. H., Schockaert, T., and Sonnemans, J. W. M ., F uel Process. Technol. 35, 111-117 (1993).

4. Miller, S. J., M icroporous M ater. 2, 439-449 (1994).

5. Jacobs, P. A ., M artens, J. A ., Weitkamp, J., and B eyer, H. K., Faraday D iscuss. Chem. Soc. 72, 353-369 (1982).

6. Chen, N. Y., and Walsh, D. E., U S patent 4,877,581 (1989).

7. Chester, A. W., Wilson, R. C., Oleck, S. M., and Y en, J. H s-G., EP patent 0155822 (1985).

8. Giannetto, G., Perot, G., and Guisnet, M., Stud. Surf. Sci. Catal. 24, 631-638 (1985).

9. D erouane, E.G., D ejaifve, P., G abelica, Z., and V édrine, J. C., Farad. D iscuss. Chem. Soc. 72, 331-344 (1981).

10. M artens, J. A ., and Jacobs, P. A ., Z eolites 6, 334-348 (1986).

11. (a) M eier, W. M ., O Ison, D. H ., and B aerlocher, Ch., "A tlas of Zeolite Structure Types," 4th ed. E Isevier, L ondon, 1996; (b) http://www.izastructure.org/databases/ by B aerlocher, Ch., and M cC usker L.B.

12. Schenk, M., Smit, B., V lugt, T. J. H ., and M aesen, Th. L. M ., A ngew. Chemie Int. Ed. Engl. 40(4), 736-739 (2001).

13. Webb, E. B., III, and G rest, G. S., Catal. L ett. 56, 95-104 (1998).

14. R aybaud, P., Patrigeon, A., and Toulhoat, H., J. Catal. 197, 98-112 (2001).

15. Siepmann, J. I., and Frenkel, D., M ol. Phys. 75, 59-70 (1992).

16. Frenkel, D., M ooij, G. C. A . M ., and Smit, B., J. P hys.: Condens. M atter. 4, 3053-3076 (1992).

17. D e Pablo, J. J., Laso, M., and Suter, U. W., J. Chem. Phys. 967, 61576162 (1992).

18. G uisnet, M ., A Ivarez, F., G iannetto, G ., and Perot, G., Catal. Today 1, 415-433 (1987).

19. Weitkamp, J., Jacobs, P. A ., and M artens, J. A ., A ppl. Catal. 8, 123-141 (1983).

20. Jacobs, P. A., U ytterhoeven, J. B., Steyns, M., Froment, G., and Weitkamp, in "Proceedings of the Fifth International Conference on Zeolites” (L. V. C. R ees, E d.), pp. 607-615. H eyden, London, 1980.

21. M artens, J. A ., Tielen, M ., and Jacobs, P. A ., A cta Chim. H ung. 119, 203-212 (1985).

22. Martens, J. A., Parton, R., U ytterhoeven, L., Jacobs, P. A., and Froment, G. F., A ppl. Catal. 76, 95-116 (1991).

23. Jacobs, P. A ., D erouane, E. G., and Weitkamp, J., J. Chem. Soc. Chem. Commun. 12, 591-593 (1981).
24. V lugt, T. J. H., K rishna, R ., and Smit, B., J. Phys. Chem. B 103, 11021118 (1999).

25. Bezus, A G, Kiselev, A. V., Lopatkin, A . A ., and D u, P. Q., J. Chem. Soc. Faraday Trans. II 74, 367-379 (1978).

26. June, R. L., Bell, A. T., and Theodorou, D. N., J. Phys. Chem. 96, 1051-1060 (1992).

27. Smit, B., and Siepmann, J. I., J. Phys. Chem. 98, 8442-8452 (1994).

28. M aesen, Th. L. M., Schenk, M., V lugt, T. J. H., D e Jonge, J. P., and Smit, B., J. Catal. 188, 403-412 (1999).

29. June, R. L., Bell, A. T., and Theodorou, D. N., J. Phys. Chem. 94, 1508-1516 (1990).

30. G iannetto, G. E., Perot, G. R ., and Guisnet, M. R ., Stud. Surf. Sci. Catal. 20, 265-272 (1984).

31. Smit, B., L oyens, L. D. J. C., and Verbist, G. L . M . M ., Faraday D iscuss. 106, 93-104 (1997).

32. Webb, E. B., III, G rest, G. S., and M ondello, M., J. Phys. Chem. B 103, 4949- 4959 (1999).

33. H aag, W. O., Lago, R. M., and Weisz, P. B., Faraday D iscuss. Chem. Soc. 72, 317-330 (1982).

34. Post, M . F. M ., Van A mstel, J., and Kouwenhoven, H. W., in "Proceedings, 6th International Z eolite Conference" (D. H. O Ison and A . B isio, E ds.), pp. 517-527. B utterworths, G uildford, 1983.

35. Voogd, P., and Van Bekkum, H., Stud. Surf. Sci. Catal. 65, 467-478 (1990).

36. N amba, S., Sato, K ., Fujita, K., K im, J. H ., and Y ashima, T., Stud. Surf. Sci. Catal. 28, 661-668 (1986).

37. Giannetto, G. E., Perot, G. R ., and Guisnet, M. R ., Ind. Eng. Chem. Prod. Res. D ev. 25, 481- 490 (1986).

38. Lugstein, A., Jentys, A., and Vinek, H., A ppl. Catal. 166, 29-38 (1998).

39. M artens, J. A ., and Jacobs, P. A ., in "Theoretical A spects of heterogeneous Catalysis" (J. B. M offat, E d.), pp. 52-109. Van N ostrand R einhold, New York, 1990.

40. H öchtl, M ., Jentys, A ., and Vinek, H ., J. Catal. 190, 419-432 (2000).

41. Weisz, P. B., A dv. Catal. 13, 137-190 (1962).

42. Coonradt, H. L., and Garwood, W. E., Ind. Eng. Chem., Prod. Res. D ev. 3, 38- 45 (1964).

43. D egnan, T. F., and Kennedy, C. R ., A IChE J. 39(4), 607-614 (1993).

44. M artens, J. A ., J acobs, P. A ., and Weitkamp, J., A ppl. Catal. 20, 283-303 (1986).

45. M artens, J. A ., Tielen, M ., and Jacobs, P. A ., Catal. Today 1, 435- 453 (1987).

46. A Ivarez, F, R ibeiro, F. R ., Perot, G., Thomazeau, C., and G uisnet, M ., J. Catal. 162, 179-189 (1996).

47. (a) Svoboda, G. D., Vynckier, E., D ebrabandere, B., and Froment, G. F., Ind. Eng. Chem. Res. 34, 3793-3800 (1995); (b) M artens, G., and Froment, G. F., Stud. Surf. Sci. Catal. 122, 333-340 (1999).

48. M artens, G. G., M arin, G. B., M artens, J. A ., Jacobs, P. A ., and B aron, G. V., J. Catal. 195, 253-267 (2000).

49. Kondo, J. N., I shikawa, H ., Y oda, E ., Wakabayashi, F., and D omen, K ., J. Phys. Chem. B 103, 8538-8543 (1999).

50. Froment, G. F., Catal. Today. 1, 455-473 (1987).

51. Weitkamp, J., in "H ydrocracking and H ydrotreating," A CS Symposium Series, Vol. 20, pp. 1-27. A m. Chem. Soc., Washington, D C, 1975.

52. D eN ayer, J. F., B ouyermaouen, A ., and B aron, G. V., Ind. Eng. Chem. Res. 37, 3691-3698 (1998).

53. K rishna, R., Smit. B., and V lugt, T. J. H ., J. Phys. Chem. A . 102, 77277730 (1998).

54. Stull, D. R., Westrum, E. F., J r., Sinke G. C., "The Chemical Thermodynamics of O rganic Compounds," pp. 249-252, 276-284. K rieger, Malabar, FL, 1987. 